\title{
O feminismo atual e necessário ${ }^{1}$
}

Emilly Marques Tenorio*

\begin{abstract}
Resumo
O artigo apresenta uma revisão da literatura sobre os rumos do feminismo no Brasil a partir de uma perspectiva materialista dialética. Busca-se refletir sobre o histórico e a importância contemporânea do movimento feminista na luta anti-patriarcal, anti-racista e anti-capitalista no cenário nacional. As análises defendem que as bandeiras de luta feministas precisam ser incorporadas pela esquerda brasileira e não serem consideradas secundárias nas lutas por transformação social que tenham como horizonte a emancipação humana e a liberdade real de homens e mulheres.
\end{abstract}

Palavras-chave: feminismo; patriarcado; emancipação.

\section{The current and necessary feminism}

\begin{abstract}
The article presents a review of the literature on the direction of feminism in Brazil from a dialectical materialist perspective. It seeks to reflect about the history and the importance of the feminist movement in the anti-patriarchal, anti-racist and anti-capitalist struggle on the contemporany national scene. The analyzes bring an argument to defend that the feminist struggle flags need to be incorporated by the Brazilian left and not considered secondary in the struggles for social transformation that aims for the human emancipation and the real freedom of men and women.
\end{abstract}

Key words: feminism; patriarchate; emancipation ${ }^{1}$

Recebido em: 03/02/2017

Aprovado em:01/05/2017

\footnotetext{
* Assistente Social do Tribunal de Justiça do Espírito Santo, Mestre em Política Social pela Universidade Federal do Espírito Santo (UFES) e Especialista em Gênero e Sexualidade pela Universidade Estadual do Rio de Janeiro (UERJ), emillypmarques@gmail.com
} 


\section{Introdução}

"Que nada nos defina. Que nada nos sujeite. Que a liberdade seja a nossa própria substância, já que viver é ser livre" (Simone de Beauvoir).

O presente artigo origina-se de uma pesquisa teórica que é parte de reflexões desenvolvidas no âmbito do mestrado, no qual discutimos especificamente a violência doméstica e familiar contra a mulher e a aplicação, pelo poder Judiciário, das medidas de proteção de urgência previstas na Lei Maria da Penha (Lei 11.340/2006) ${ }^{2}$. Debater o feminismo se fez basilar, não só em virtude da nossa própria atividade militante, mas também por compreendermos que as respostas estatais, além de limitadas, não surgem espontaneamente, mas são obtidas via tensionamentos e lutas sociais.

"Feminismo" tem sua origem na palavra francesa "femme" que significa mulher. O termo é usado, portanto, para abordar a vida das mulheres, compreendê-la e buscar sua emancipação. Por isso, feminismo é, ao mesmo tempo, um posicionamento diante da vida, uma lente de análise crítica sobre a realidade das mulheres e um movimento social (SILVA; CAMURÇA, 2013).

Cotidianamente, tornou-se comum ouvir de homens e mulheres que as desigualdades entre os sexos se findou, pois, atualmente, nós somos "livres". Os argumentos giram em torno de que as mulheres estão inseridas no mercado de trabalho, estudam, "optam" ou não pelo exercício da maternidade e na escolha de seus parceiros ou parceiras, dentre outras questões. É um mundo "sem preconceitos", onde supostamente a mulher conquistou seus espaços e seu "lugar", não sendo mais necessário um tratamento específico para ela e que estudos sobre tais desigualdades são ultrapassados e desnecessários, assim como o próprio movimento feminista.

Cynthia Sarti define o(s) feminismo(s) como uma experiência histórica que aborda "genérica e abstratamente a emancipação feminina e, ao mesmo tempo, atua dentro dos limites e das possibilidades - que lhe são intrínsecos - de se referir concretamente a mulheres em contextos políticos, sociais, culturais e históricos específicos” (SARTI, 2001, p. 31).

Dominique Fougeyrollas-Schwebel (2009) acrescenta que o feminismo enquanto movimento coletivo de luta se inscreve no reconhecimento que as desigualdades entre homens e mulheres não são naturais e por isso são passíveis de transformação. Porém, os feminismos diferenciam-se quanto à definição da opressão das mulheres e quanto às estratégias políticas. 
A autora expõe que existem muitas distinções, porém a "oposição politicamente mais frontal recai sobre as feministas liberais, de um lado, e feministas radicais e socialistas, de outro" (FOUGEYROLLAS-SCHWEBEL, 2009, p. 147). O feminismo liberal considera possíveis reformas e políticas positivas e promoção de valores individuais para estabelecer a igualdade entre homens e mulheres. Já o feminismo radical e o socialista querem romper com as estruturas sociais existentes (FOUGEYROLLAS-SCHWEBEL, 2009).

Para nós, a liberdade é o princípio fundamental do(s) feminismo(s). Porém, ressaltamos que dependendo do horizonte teórico a que a vertente do feminismo se vincula, a liberdade pode ter significados diferenciados. Segundo Ivo Tonet (2009) a liberdade essencialmente vincula-se à autodeterminação, mas essa liberdade pode ser formal ou real. A liberdade formal atrela-se à conquista da cidadania e de direitos, a uma autodeterminação jurídico-política, uma emancipação política. Já a liberdade real só é possível de ser alcançada com a emancipação humana em outro modo de sociabilidade.

Primeiramente, destacamos que os avanços para a conquista da liberdade formal das mulheres não se deram sem árduas lutas feministas e não podemos considerá-las insignificantes já que tiveram efeitos concretos na vida das mulheres, porém precisamos reconhecê-las como limitadas, pois não atingem a liberdade plena.

Dessa forma, se na atualidade identificamos mudanças nas formas de opressão de mulheres - pois "como os demais fenômenos sociais, também o patriarcado está em permanente transformação" (SAFFIOTI, 2004, p.45, 46) -, alguns avanços da luta feminista podem ser considerados compatíveis com este sistema de opressão, já que ao se restringirem à esfera legal-técnica-normativa não promovem mudanças substantivas, ou seja, a real emancipação política das mulheres, adaptando-se às necessidades do modo exploratório capitalista que, para se conservar, garante alguns poucos direitos. Como nos alerta Tonet (2009), vivencia-se uma sociabilidade em que as pessoas são apenas iludidas com a liberdade, pois quem é realmente livre é o capital.

Dividimos, a fim de exposição, o artigo em três momentos. No primeiro, realizamos alguns apontamentos sobre a história do movimento feminista brasileiro que permanece em constante (re)construção e, posteriormente, refletimos sobre a importância das bandeiras feministas históricas serem incorporadas como bandeiras da luta ampliada da esquerda nacional em direção à construção de uma nova ordem societária, demarcando as especificidades do feminismo latino-americano, que já nasce atrelado às pautas da esquerda (SHILD, 2016) para, enfim, tecermos nossas reflexões conclusivas. 


\section{Breves apontamentos sobre o movimento feminista brasileiro}

O objetivo deste tópico é abordar a história do movimento feminista brasileiro e os avanços em relação à emancipação política das mulheres. Tais lutas no Brasil, inicialmente estiveram ligadas à educação e ao voto. Antigamente, até início do século XX, o acesso ao ensino era exclusivo dos homens e negado às mulheres e aos escravos. Sérgio Carrara et al (2010, p. 73) citam ditos populares do século XIX: "Mulher que sabe latim não tem marido, nem bom fim" e "Escravos que sabem ler, acabam querendo mais do que comer". De acordo com o autor, as estudantes brasileiras esperaram até 1879 para a entrada em faculdades, mesmo assim as solteiras deveriam ter autorização dos pais e as casadas, dos maridos (CARRARA et al, 2010).

Em nosso país, também ocorreram algumas iniciativas individuais de reivindicação ao direito de votar e ser votada no final do século XIX. As sufragistas brasileiras, do início do século XX, influenciadas pelas conquistas internacionais, somaram-se aos movimentos de esquerda emergentes e às primeiras greves operárias (CARRARA et al, 2010). Porém, o voto feminino só foi autorizado no Código eleitoral Provisório (Decreto 21076), em 24 de fevereiro de 1932, mesmo assim limitado às mulheres casadas com autorização do marido, ou mulheres que tivessem renda própria. Até o Código Eleitoral de 1965, permaneceram as restrições ao voto feminino, salvo àquelas mulheres que exerciam uma profissão remunerada (ALVARES, 2014).

Dessa forma, à "primeira onda feminista", agitada em âmbito internacional principalmente por mulheres burguesas, é atribuída esta luta pelos direitos civis e políticos, o acesso à educação e ao voto, com o enfrentamento de entraves culturais e legais:

\footnotetext{
Não só o direito do voto foi reclamado, mas a instrução incipiente e a falta de leis para ampliar a educação superior e abrir áreas profissionais que estavam restritas aos homens foram demandas de mulheres das classes privilegiadas. $O$ não voto para as mulheres era justificado pela educação diferenciada e pelos papéis sociais que cristalizavam a conduta masculina e a feminina com influências da cultura patriarcal. [...] Se o voto feminino era negado como uma ameaça à maternidade e à vida doméstica, a liderança das mulheres, nos movimentos de protesto, não sofria restrição [...] (ALVARES, 2014, p.160).
}

No Brasil, essa primeira onda feminista ocorre do final do século XIX ao início do século XX e associa-se a causas proletárias com reivindicações por melhores condições de 
trabalho (salários, redução da jornada e salubridade), representadas por exemplo, pelas operárias de ideologia anarquista, trabalhadoras de indústrias têxteis brasileiras (MARTINS, 2015).

Em nível nacional, a "segunda onda feminista" inicia-se a partir da segunda metade do século XX, com convergência com as pautas da esquerda nacional. Segundo Costa (2005 p.15) a diferença principal do feminismo latino-americano é que, diferentemente das militantes das correntes majoritárias do movimento feminista europeu e norte-americano, as mulheres latino-americanas já se alinhavam "com uma mudança radical das relações sociais de produção, enquanto continuavam lutando contra o sexismo dentro da esquerda", agregando um projeto societário, que incluía os setores populares, "em outras palavras, as feministas latino-americanas estiveram sempre marcadas pela dinâmica social, política e econômica da região" (SHILD, 2016, p.66).

Verônica Schild (2016, p.62) argumenta, nesse sentido, que o feminismo latinoamericano possui características específicas, em virtude de sua realidade material e cultural e seus contextos sócio-históricos. Relembra que os movimentos feministas latino-americanos fortaleceram-se na luta contra regimes opressores, não se constituindo em uma luta liberal, individual ou a-classista:

Os movimentos feministas dos anos 1970 emergiram no curso das lutas revolucionárias contra os regimes severamente repressivos: juntas militares tomaram o poder no Brasil em 1964, na Bolívia em 1971, no Uruguai e no Chile em 1973 e na Argentina em 1976, instituindo ditaduras tecnocráticas que usaram da tortura e de desaparecimentos e assassinatos para eliminar a esquerda, destruir os sindicatos e desmobilizar a sociedade civil. [...] Em contraste com a "dona de casa" da OCDE [Organização para a Cooperação e Desenvolvimento Económico], a maioria das mulheres latino-americanas trabalhavam - na terra ou como serventes domésticas enquanto as mulheres da elite foram liberadas das tarefas domésticas por suas empregadas.

Neste período, amadurecem-se os questionamentos do espaço privado e das relações patriarcais de submissão e violência reproduzidas na família:

Ao afirmar que "o pessoal é político", o feminismo traz para o espaço da discussão política as questões até então vistas e tratadas como específicas do privado, quebrando a dicotomia público-privado, base de todo o pensamento liberal sobre as especificidades da política e do poder político. Para o pensamento liberal, o conceito de público diz respeito ao Estado e às suas instituições, à economia e a tudo mais identificado com o político. Já o privado se relaciona com a vida doméstica, familiar e sexual, identificado com o pessoal, alheio à política (COSTA, 2005, p.10). 
Traziam em seu seio questionamentos contra o tradicional papel social atribuído às mulheres, à tutela marital e iniciam o debate sobre direitos sexuais e reprodutivos, com lemas como "Nosso corpo nos pertence" e "Diferentes, mas não desiguais" (CARRARA et al, 2010). Segundo Martins (2015, p.234),

[...] o movimento incorpora pautas culturais, desta vez relacionadas ao questionamento dos padrões sociais que atribuem a homens e a mulheres papéis específicos nas relações afetivas, na vida política e no trabalho, o que estaria na base da preservação de desigualdades. Nesse momento, em que direitos políticos e civis já estavam em processo de consolidação em diversos países ocidentais, estabeleceram-se os alicerces de uma teoria feminista, destinada a compreender as origens e as causas das desigualdades entre os sexos.

No contexto de luta pela redemocratização, as feministas somaram-se aos protestos contra a ditadura, na busca por direitos de cidadania, igualdade e sexualidade, principalmente nos anos 1970 e 1980 (CARRARA et al, 2010). Nestas décadas iniciam-se no âmbito acadêmico os "estudos de gênero", que contemplam diversas polêmicas e perspectivas, envolvendo debates com diversas (e por vezes opostas) matrizes teóricas, como o marxismo, a psicanálise, o pós-estruturalismo e o pós-modernismo, sendo uma das críticas de autoras materialistas, como Mirla Cisne (2012), que tais abordagens desconstrutivistas obscureceram o sujeito mulher e sua inserção na sociedade patriarcal-racista-capitalista. Parece que se fala mais em "teorias de gênero" do que em "teorias feministas", pois se torna mais "palatável".

Para além do espaço acadêmico, permanecia a militância feminista nas ruas pela redemocratização aliada a outros movimentos sociais e sindicais e profundamente vinculada aos "setores de esquerda". Representando um dos segmentos mais diversificados, a mobilização das mulheres na Constituinte de 1988 se expressou na "Carta das Mulheres à Assembleia Constituinte" e na atuação dos grupos que ficaram conhecidos como o "lobby do batom", com muitas pautas atendidas na luta por uma legislação mais igualitária (COSTA, 2005).

Segundo Ana Paula Martins, na década de 1960 ocorreram diversas convenções relacionadas às demandas das mulheres com resultados expressados em pactos internacionais, especialmente em espaços multilaterais, como as instâncias da Organização das Nações Unidas. A autora explicita que, globalmente, os movimentos feministas adotaram uma estratégia "que direciona parte significativa de seus esforços e de suas lutas para a arena jurídica e institucional” (MARTINS, 2015, p. 235).

No Brasil, muitos dos pactos instituídos foram adotados tardiamente, somente nos 
anos 1990, sendo o país, inclusive, considerado omisso pela Organização dos Estados Americanos (OEA), quando chega a este espaço a denúncia do caso da biofarmacêutica Maria da Penha, mulher branca com ensino superior, vítima de violências e tentativas de homicídio perpetradas pelo marido, uma das quais a deixou paraplégica. A condenação da OEA resultou na recomendação de que nosso país "desenvolvesse uma série de medidas para combater a violência contra as mulheres, o que resultou, em 2006, na promulgação da Lei Maria da Penha" (MARTINS, 2015, p.235).

Nos anos 1980, o movimento feminista passou por um processo de "ongnização", com um trabalho mais especializado e profissional frente ao Estado e na exigência de políticas públicas (COSTA, 2005). A hegemonia das Organizações Não Governamentais (ONGs) foi alvo de preocupação de muitas militantes, principalmente aquelas vinculadas aos setores de esquerda, o que Fougeyrollas-Schwebel (2014, p.148) qualifica de evolução contraditória dos movimentos feministas, pois justamente quando "a pressão internacional permite o avanço dos direitos das mulheres, [ele é] acompanhado de uma atenuação da radicalidade dos movimentos feministas, que passam a se posicionar como associações a serviço das mulheres".

A "terceira onda feminista", iniciada em meados de 80 e nos anos 90 dedica-se, sobretudo, à questão da diversidade entre as mulheres, contrárias ao universalismo e essencialismos do sujeito "mulher" (MARTINS, 2015). Adquirem maior visibilidade as organizações das mulheres negras, na luta contra o racismo e a subordinação sexual e contra a universalização do sujeito mulher. Elas denunciam que as pautas das mulheres negras são diferenciadas daquelas do "feminismo branco", sendo um dos exemplos, o fato de que a reivindicação das mulheres brancas para "trabalhar fora", como elemento de emancipação, era, ao contrário, um elemento de opressão sempre presente no cotidiano das mulheres negras, que tiveram seu trabalho explorado e apropriado não só pelos homens mas também pelas mulheres brancas.

Bebel Nepomuceno denuncia que o protagonismo das mulheres negras foi historicamente ignorado e que suas trajetórias foram diferenciadas daquelas das mulheres brancas, pois não experimentaram as mesmas formas de submissão: "Partiram de patamares desiguais e, no desenrolar dos acontecimentos, não caminharam juntas nem no mesmo passo, com determinadas situações de nítidos privilégios [...]” (NEPOMUCENO, 2013, p. 383).

A autora expõe que às negras sempre foi necessária a luta pela sobrevivência e, para tanto, circulavam pelas ruas "ao contrário do prescrito para a mulher idealizada da época" e 
muitas viviam em famílias sem a presença masculina, sendo as principais e/ou únicas responsáveis pelo atendimento às necessidades da prole: "não havia muito espaço para a imagem da esposa passiva, submissa ao marido e dedicada exclusivamente ao lar" (NEPOMUCENO, 2013, p. 387).

Outro elemento destacado pela autora, é que o espaço privado, para as mulheres negras, sempre foi, ao mesmo tempo, local de produção econômica, inicialmente nos cortiços e, posteriormente, nas favelas ou outros locais periféricos, que se transformavam em suas lavanderias ou em cozinhas para preparação dos salgados e quitutes para venda, além de serem lócus de convívio social e religioso. Sobre a questão da negritude e de suas pautas específicas, é presente também no feminismo negro o debate sobre o corpo que denuncia a objetificação e hiperssexualização da mulher negra.

No feminismo, de forma ampla, o corpo é novamente pautado em movimentos como "SlutWalk"ou "Marcha das Vadias" que ganham mais adeptas e dão visibilidade ao feminismo, reforçando as bandeiras da "segunda onda", incluindo o tema "Meu corpo, minhas regras", a diversidade de orientação sexual, e a denúncia da violência sofrida por mulheres lésbicas e bissexuais, além das questões identitárias como ocorre com as travestis e transexuais.

Conforme exposto, alguns/algumas estudiosos/as, para fins didáticos, periodizam as bandeiras de luta e estratégias feministas, dividindo-as em "ondas" (COSTA, 2005; CARRARA et al, 2010; PINTO, 2010; MARTINS, 2015). Primeiramente, chamamos a atenção de que a palavra "onda" pode não definir bem o movimento, já que a "onda" é oscilante, instável e as lutas por uma igualdade substantiva e pela emancipação feminina se refletem na atividade diuturna das mulheres, que estão atentas, inclusive às possibilidades de retrocesso de direitos conquistados. Ademais, a história não se apresenta de forma estática, não sendo possível efetuar tais divisões. Consideramos que o movimento feminista não é uma massa homogênea, além do fato de não ocorrer isolado do contexto mundial (COSTA, 2005).

Costa aborda que, nos anos 90, se multiplicaram as várias modalidades de organizações e identidades feministas:

As mulheres pobres articuladas nos bairros através das associações de moradores, as operárias através dos departamentos femininos de seus sindicatos e centrais sindicais, as trabalhadoras rurais através de suas várias organizações começaram a auto-identificar-se com o feminismo, o chamado feminismo popular. As organizações feministas de mulheres negras seguem crescendo e ampliando a agenda política feminista e os parâmetros da própria luta feminista (COSTA, 2005, p. 19). 
Atualmente vivenciamos a reatualização e diversificação do feminismo com maior difusão e popularização do movimento, principalmente com o auxílio da internet e das redes sociais, atingindo gerações mais novas, mas com a permanência de pautas históricas, como o direito de viver sem violência, cujo principal expoente foi a aprovação da já citada "Lei Maria da Penha" em 2006, que aborda a violência doméstica e familiar contra a mulher.

Além disso, tivemos os protestos recentes em 2015, pela legalização e descriminalização do aborto, reavivados em virtude do PL 5069/2013 - que dificulta o acesso aos permissivos legais à interrupção da gravidez previstos no Artigo 128 do Código Penal Brasileiro, desde 1940 - ter sido aprovado na Comissão de Constituição e Justiça e de Cidadania da Câmara dos Deputados. Tais protestos, que ocorreram em todo o território nacional, foram denominados por alguns veículos de comunicação como "Primavera das Mulheres"3.

\section{Porque a luta das mulheres não pode ser secundarizada nas pautas da esquerda?}

Buscando trazer elementos a um debate histórico na esquerda de que apenas a classe é a categoria necessária para debater e enfrentar o sistema em que vivemos, trabalhamos em outra direção, defendendo que a análise das explorações e das opressões não podem ser hierarquizadas ou indissociadas, na perspectiva da consubstancialidade ${ }^{4}$ entre sexo $^{5}$, raça e classe, cunhado por Daniele Kergoat.

Kergoat (2010) definirá que os sistemas exploratórios se estruturam no sexo, na raça e na classe, sendo necessária a análise indissociável destes três elementos. Expõe que eles são consubstanciais, formam um "nó" que não pode ser desatado nas práticas sociais e sua propriedade principal é a coextensibilidade pois um retroalimenta o outro, ou seja, se produzem e reproduzem mutuamente.

Silvia Federici enfatiza que a história das mulheres não pode ser separada da história dos sistemas de exploração, pois "as hierarquias sexuais sempre estão a serviço de um projeto de dominação que só pode sustentar-se a si mesmo através da divisão, constantemente renovada, daqueles a que se quer governar" (FEDERICI, 2015, p. 12, tradução nossa) ${ }^{6}$.

A sociedade capitalista é permeada pela busca pela reprodução ampliada do capital e fundamenta-se na complexa divisão social e sexual do trabalho, na preservação da 
propriedade privada e do patrimônio, e nas relações de poder entre classes, entre homens e mulheres, e entre raças/etnias. Desta forma não é o sexo que divide a classe e sim o capitalismo que reforça tais divisões, funcionais ao mesmo, facilitando, inclusive seu projeto de dominação.

Neste tópico, dialogamos com Silvana Mara Santos que tece uma crítica à "esquerda tradicional", que:

tendo sido formada na trilha do movimento operário, foi acusada de ser economicista na compreensão da vida social e de não valorizar as questões voltadas à individualidade por considerá-las situações menores. Esse legado insiste em se reproduzir, especialmente, no âmbito partidário. Por seu intermédio, exploração e opressão são entendidas de modo separado e pensar numa dessas modalidades significa desvalorizar a outra. (SANTOS, 2005, p. 18).

Para a autora, tal equívoco mecanicista redunda numa "objetividade economicista" que desconsidera a subjetividade e a diversidade entre os sujeitos que compõe este modo de vida exploratório e reprodutor de opressões. Descreve uma nova tendência no pensamento da esquerda, a qual conceitua como "esquerda democrática" que mantém interlocução política com segmentos organizados em torno da política da identidade, da diversidade e da diferença, agregando em suas pautas a luta contra o machismo, o racismo e a homofobia (SANTOS, 2005). Expondo a importância da política de identidade adentrar as pautas da esquerda, Santos entende que tal política se refere:

[...] ao conjunto de questões sócio-culturais relacionadas, dentre outras, às relações sociais de gênero; etnia; raça; orientação sexual que incidem na formação da individualidade, passando a se constituir reivindicações políticas, sobretudo, a partir da década de 1960, em nível mundial, e em 1970, no Brasil através dos movimentos sociais (SANTOS, 2005, p.16).

Ademais, a relevância e necessidade da luta feminista está comprovada por dados estatísticos que demonstram o quão cruel ainda é a diferenciação de tratamento, comportamentos e expectativas sociais depositadas em homens e mulheres, assim como a permanência estrutural da divisão sexual e racial do trabalho, relações sociais que possuem uma base material e não puramente ideológica, tomando corpo nas instituições e legislações que as legitimam (KERGOAT, 2009).

Consideramos necessário atermo-nos a análise a partir de uma perspectiva críticaontológica-materialista na compreensão da constituição da mulher enquanto ser social. O ser social possui como categoria fundante o trabalho, porém as capacidades de se objetivarem 
no/pelo trabalho sempre foram limitadas às mulheres, ou seja, em nossa perspectiva, a mulher se constitui de forma socialmente desigual.

Paola Tabet (2014, p. 107) sustenta a tese de que mesmo nas sociedades ditas "igualitárias", da caça e da coleta, há uma relação de dominação, uma divisão do trabalho que "não é neutra, mas orientada e assimétrica", pois a divisão sexual do trabalho é uma relação política entre homens e mulheres. A autora defende que há uma diferença qualitativa e quantitativa dos instrumentos à disposição de cada um dos sexos, além de uma generalizada situação de subequipamento das mulheres. Isso se ampliou progressivamente conforme o aprimoramento técnico das sociedades industrializadas. Essas diferenças entre os instrumentos de cada sexo acarretaram diferenças de tempo livre entre homens e mulheres, já que com técnicas diferenciadas, aos homens foi garantido maior tempo livre, reduzindo o tempo das mulheres para o lazer e outras atividades intelectuais, sendo que "esta expropriação do tempo das mulheres é um aspecto fundamental de sua exploração" (TABET, 2014, p.124).

Seguindo essa análise, ontologicamente as mulheres possuem particularidades objetivas e subjetivas, e tiveram limitações no seu processo de desenvolvimento enquanto ser social, como a aquisição de habilidades físico-cognitivas e o acesso aos instrumentos e armas, ou seja, tiveram suas escolhas entre alternativas limitadas.

Outro processo de controle ao qual as mulheres foram submetidas foi a sexagem. Falquet (2008) explicará que o conceito de sexagem foi cunhado por Colette Guillaumin e se refere à apropriação da classe social de sexo das mulheres pela classe social de sexo dos homens. Diz que a sexagem não é como a exploração ou apropriação da força de trabalho, mas uma apropriação da pessoa inteira, do seu corpo como um todo, dos seus produtos, do tempo das mulheres e de sua energia psíquica, ou seja, é uma apropriação física direta, “a redução ao estado de coisa, mais ou menos admitida ou conhecida para as relações de escravidão e de servidão" (GUILLAUMIN, 2014, p. 51).

Dessa forma, não apenas sua força de trabalho é explorada de forma desvalorizada e suas possibilidades não foram plenamente desenvolvidas, mas seu corpo como um todo é materialmente apropriado, de uma forma tão naturalizada que se torna invisível. Dessa forma tais processos são estruturais. Podemos ter avançado em algumas relações interpessoais, nas quais as mulheres não aceitam mais este lugar inferiorizado e constroem outras formas de organização do trabalho doméstico, mais coletivizadas entre todos os membros da casa, bem como não se submetem os seus desejos ao do outro. Porém, transformações nas relações intersubjetivas, embora importantes, não modificam as relações estruturais, consubstanciais, 
de sexagem e subserviência, nas quais as mulheres são apropriadas como coisas ao serviço do outro, usurpando delas o prazer e o tempo livre:

A distinção entre relação intersubjetiva e relação social permite compreender que se a situação mudou de fato em matéria de relações intersubjetivas entre os sexos e nos casais, as relações sociais, porém continua a operar e a se manifestar sob três formas canônicas: exploração, dominação e opressão (que podem ser ilustradas pelas diferenças salariais, pela maior vulnerabilidade e maior risco de ser vítima de violências). (KERGOAT, 2010, p. 95).

Nesta direção, Mészáros expõe que as relações igualitárias, intersubjetivas, não podem se generalizar nos marcos desta sociedade capitalista, pois "pares isolados podem ser capazes de ordenar (o que certamente fazem) seus relacionamentos pessoais em verdadeira igualdade [...]" (MÉSZÁROS, 2011, p. 269), porém essas relações não podem se tornar historicamente dominantes.

Kergoat expõe que as relações sociais de sexo contêm um paradoxo: "Simultaneamente à melhora da situação da mulher, em particular no mercado de trabalho, ocorre a persistência, às vezes mesmo intensificação, da divisão sexual do trabalho. Tudo muda para tudo permanecer igual" (KERGOAT, 2010, p. 94). Para a autora isso se deve ao fato do capitalismo necessitar desta mão de obra "flexível" e que mesmo com o aumento da participação no mercado de trabalho, as segmentações entre empregos femininos e masculinos permanecem, bem como as diferenças salariais.

O discurso de que a igualdade foi alcançada também utiliza o comum argumento de que "homens e mulheres são iguais perante a lei", que é fetichizado e não traduz a realidade, circunscrevendo-se aos limites da emancipação política e sem considerar que nem essa foi alcançada plenamente. Lênin, em um discurso às operárias em 1920, já falava que "a igualdade diante da lei não é ainda a igualdade efetiva", justificando que onde existe exploração não pode existir igualdade e que, mesmo na construção de uma nova sociedade sem exploradores (capitalistas, latifundiários e comerciantes), só a lei não basta. O pensador marxista tecia seu discurso num contexto histórico pós-revolucionário, no qual ocorreriam eleições no soviete de Moscou em que:

O poder dos sovietes aboliu completamente todas as velhas leis burguesas, as abomináveis leis que punham a mulher num estado de inferioridade em relação ao homem, que reconheciam ao homem, para citar apenas um exemplo, uma posição de privilégio na esfera do direito matrimonial e das relações com os filhos. Primeiro e 
único no mundo, o poder dos sovietes, como poder dos trabalhadores, aboliu todas aquelas vantagens que, originadas da propriedade, ainda hoje são atribuídas ao homem no direito familiar nas repúblicas burguesas mais democráticas (LENIN, 1920, s.p.).

A historiadora Wendy Goldman (2014) disserta sobre a breve e grande experiência histórica de libertação da mulher e amor livre, após a Revolução de outubro de 1917, que definhou com a posterior direção burocrática e repressora stalinista e a relevância de estudarmos a datada experiência soviética como um direcionamento para transformações sociais futuras:

\begin{abstract}
Tais experiências sugerem que se criarmos pleno emprego e salários com os quais possamos viver de fato, para homens e mulheres, a independência para ambos os sexos virá como consequência. Se as mulheres tiverem acesso ao aborto legal e seguro, opção de controle de natalidade saudável e bons cuidados médicos, elas poderão exercer sua liberdade sexual. Se os homens assumirem responsabilidades iguais pelos filhos e pelas tarefas domésticas, as mulheres poderão se realizar como seres humanos iguais. Creches, restaurantes públicos e lavanderias, tudo isso para que as mulheres possam se livrar do fardo dos afazeres domésticos e cuidados com os filhos, os quais normalmente têm de suportar (GOLDMAN, 2014, p. 12)
\end{abstract}

Goldman (2014) expõe que tais ações se deram no período imediato após a Revolução de 1917. O trabalho doméstico foi substituído pelo trabalho assalariado na esfera pública. O objetivo era criar condições concretas para independência e liberação das mulheres. Porém, as contradições que afloraram na sociedade soviética não permitiram o prosseguimento das ações. Desta forma, podemos apreender que tal debate sobre estratégias para emancipação feminina não pode se desconectar do debate mais amplo sobre a construção de um novo modelo de sociedade. Quando esses dois debates se dissociam, há convergência de certas formas de feminismo com a agenda neoliberal e aos ajustes estruturais, trazendo ambiguidades que podem servir à legitimação do capitalismo (SCHILD, 2016).

Tal lógica vem sendo fortemente delineada no contexto latino-americano. Na garantia de "mínimos sociais" as políticas sociais da última década têm voltado-se para a gestão da pobreza e focalizado principalmente as mulheres, apropriando-se do discurso do feminismo liberal de "empoderamento" e autonomia individual, fetichizando as bases exploratórias deste modo de produção, o que é um processo histórico que não se restringe a essa década, mas nela ganha maior visibilidade. Para Verônica Schild (2016, p. 68), "esta institucionalização da busca feminista por autonomia, ou 'empoderamento', tem criado incontestavelmente um novo espaço para as mulheres - ao mesmo tempo em que as enganam novamente em relações opressivas e muitas vezes exploradoras" (SCHILD, 2016, p. 68). 


\section{Considerações finais}

O feminismo permanece com diferentes vertentes e visões teóricas sobre a realidade que se refletem em diversas formas de organização político-associativa e bandeiras de luta. Defendemos uma perspectiva feminista fundamentada no materialismo histórico dialético, baseada no entendimento das assimetrias de poder construídas historicamente nas relações sociais, que considera as dimensões de sexo, raça e classe de forma indissociável tanto na análise desse sistema exploratório e opressor quanto nas suas estratégias de enfrentamento.

Discordamos parcialmente de Leidiane Oliveira $(2015$, p. 6) que defende que se faz "necessário romper, primordialmente com a desigualdade de classe, sob pena de, sem ela, dada a impossibilidade da emancipação humana, não podermos alcançarmos a igualdade substantiva", pois adotamos as concepções do feminismo materialista, classista e antirracista, que busca uma compreensão crítica da realidade para nela intervir "na luta contra as relações patriarcal-racista-capitalistas e em defesa da emancipação humana" (CISNE, 2014, p. 135) e em busca de uma igualdade substantiva e da liberdade real (TONET, 2009) que articule as três dimensões de forma consubstancial, imbricada. No entanto, concordamos com Oliveira (2015, p. 7) quando esta aborda que:

\footnotetext{
No campo das contradições contemporâneas situamos o capitalismo e o patriarcado, como objeções ao processo de desenvolvimento das capacidades humanogenéricas, especialmente das mulheres. O movimento de alienação corrobora com desvalores (valores que não se constroem na perspectiva da emancipação humana, mas da desvalorização dos sujeitos), como o preconceito, o racismo, a intolerância, o machismo.
}

Simone de Beauvoir ([1949] 2009) já expunha que, mesmo quando o estatuto legal da mulher é igual ao do homem, seus direitos são só abstratamente reconhecidos, pois não encontram sua expressão concreta nos costumes. Tal hierarquia, construída num processo de sexagem, de apropriação do corpo das mulheres, reserva ao feminino um lugar inferior, justificando e naturalizando atos violentos como "corretivos" aos comportamentos "desviantes" das convenções sociais, ou seja, entendendo-os como cometidos em defesa da honra e dos "bons costumes".

A complexidade dessa forma de opressão exige-nos formas de enfrentamento desenvolvidas por diferentes sujeitos sociais, espaços socioinstitucionais, porém também e, talvez o mais central, nos espaços auto-organizados de mulheres ocupando espaços de conselhos, coletivos, grupos de estudo/núcleos de pesquisa, além de espaços setoriais ou 
grupos específicos dentro de movimentos sociais ou partidos políticos nas organizações de esquerda, em uma luta antipatriarcal, antirracista e anticapitalista, tendo a emancipação humana no horizonte.

Dessa forma, o feminismo é central para uma nova ordem social, assim como uma nova ordem social é necessária para o feminismo, pois a luta pelo fim da opressão da mulher, também é a luta pelo fim da sociedade de classes e pelo fim do racismo. Cabe-nos destacar, que, se os elementos trazidos pela luta feminista na construção da emancipação feminina, forem desconsiderados, não adiantará a abolição das classes e da propriedade privada, pois além da transformação das bases materiais, é fundamental a construção de novos valores contra hegemônicos, o que também deve ocorrer no espaço da família:

O aspecto mais importante da família na manutenção do domínio do capital sobre a sociedade é a perpetuação - e a internalização - do sistema de valores profundamente iníquo, que não permite contestar a autoridade do capital, que determina o que pode ser considerado um rumo aceitável de ação dos indivíduos que querem ser aceitos como normais, em vez de desqualificados por "comportamento não conformista” (MÉSZÁROS, 2011, p. 271, grifos do autor).

Podemos concluir, portanto, que a mulher ser considerada inferior ao homem não é um dado natural, mas socialmente construído, pois o próprio acesso que ela teve à tecnologia foi diferenciado, constituindo-na de maneira diversa na relação com a natureza (ambas, natureza e mulher, dominadas pelo homem). Em outras palavras, enquanto ser social, ontologicamente, a mulher se coloca nessa condição de submissão, mas como isso é algo socialmente construído e não natural, também pode ser socialmente superado. Assim como a dominação do homem pelo homem na configuração das classes, também se relaciona com quem é proprietário dos meios de produção, sendo uma relação socialmente construída a ser superada coletivamente.

Mirla Cisne (2014) destaca que na sociedade capitalista os homens também são explorados e alienados dos frutos de seu trabalho, mas as mulheres são marcadas pela naturalização de seus comportamentos, sendo consideradas "apolíticas, passivas e submissas" (CISNE, 2014, p. 15), desta forma, a organização coletiva, política e crítica das mulheres, nos marcos desta sociedade, é atual e necessária e as dimensões da luta antipatriarcal, antirracista e anticapitalista deverão estar articuladas, não havendo prioridade hierárquica de uma sobre as outras. 


\section{Referências bibliográficas}

ÁLVARES, Maria Luzia Miranda. Entre eleitoras e elegíveis: as mulheres e a formação do eleitorado na democracia brasileira - quem vota? quem se candidata? .Cadernos Pagu. n. 43, p.119-167, jul.o-dez.2014. Disponível em: <http://www.scielo.br/pdf/cpa/n43/0104-8333-cpa-43-0119.pdf.>. Acesso em 25 de março de 2016.

BEAUVOIR, Simone de. O segundo sexo. Rio de Janeiro: Nova Fronteira, [1949] 2009.

CASTRO, Bárbara, RONCATTO, Mariana. Entrevista com Helena Hirata. Revista Ideias. Trabalho de Mulheres, vol 7, n.1, 2016. Disponível em: <http://www.ifch.unicamp.br/ojs/index.php/ideias/article/view/2293 >. Acesso em 10 de outubro de 2016.

CARRARA, Sérgio et al. Gênero. In: CARRARA, Sérgio et al. Curso de Especialização em Gênero e Sexualidade. Rio de Janeiro: CEPESC; Brasília: Secretaria Especial de Políticas para Mulheres, 2010.

CISNE, Mirla. Gênero, Divisão sexual do Trabalho e Serviço Social. São Paulo: Editora Outras Expressões, 2012 .

. Relações sociais de sexo, "raça/etnia e classe: uma análise feminista-materialista. Revista Temporalis, n. 28, p. 133-149, jul./dez. 2014.

COSTA, Ana Alice Alcântara. O movimento feminista no Brasil: dinâmicas de uma intervenção política. Revista Gênero. Niterói, v. 5, n. 2, p. 9-35, 1. sem. 2005. Disponível em: <http://www.revistagenero.uff.br/index.php/revistagenero/article/view/380>. Acesso em 25 de março de 2016.

FALQUET, Jules. Repensar as relações sociais de sexo, classe e "raça" na globalização neoliberal. Mediações, vol. 13, n. 1-2, p. 121-142, jan-jun e jul-dez, 2008,

FEDERICI, Silvia. Calibán y la bruja: mujeres, cuerpo y acumulación originaria. Ciudad Auntónoma de Buenos Aires: Tinta Limón, 2015.

FOUGEYROLLAS-SCHWEBEL, Dominique. Movimentos feministas. In: HIRATA, Helena et al (orgs). Dicionário crítico do feminismo. São Paulo: Editora UNESP, 2009. p. 144-146.

GOLDMAN, Wendy. Mulher, Estado e Revolução. São Paulo: Boitempo, 2014.

GUILLAUMIN. Collete. Prática do poder e ideia de natureza. In: FERREIRA, Verônica et. al. (orgs.) $O$ Patriarcado desvendado: teorias de três feministas materialistas: Collete Guillaumin, Paola Tabet e Nicole Claude Mathieu. Recife: SOS Corpo, 2014. p. 27-100.

KERGOAT, Danièle. Divisão sexual do trabalho e relações sociais de sexo. In: HIRATA, Helena et. al. Dicionário Crítico do Feminismo. São Paulo: Editora Unesp, 2009, p. 67-75.

. Dinâmica e consubstancialidade das relações sociais. Novos estudos - CEBRAP, São Paulo, n. 86, p. 93-103, março, 2010. Disponível em: 〈http://www.scielo.br/pdf/nec/n86/n86a05.pdf〉. Acesso em 14 de março de 2016.

LÊNIN, Vladimir. Às operárias. 22 de fevereiro de 1920 . Disponível em: <https://www.marxists.org/portugues/lenin/1920/02/22.htm>. Acesso em 01 de agosto de 2016.

MARTINS, Ana Paula Antunes. O Sujeito "nas ondas" do Feminismo e o lugar do corpo na contemporaneidade. Revista Café com Sociologia, v.4, n.1. jan. - abr. 2015. Disponível em: <http://revistacafecomsociologia.com/revista/index.php/revista/article/view/443〉. Acesso em 25 de março de 2016. 
MÉSZÁROS, István. A liberação das mulheres: a questão da igualdade substantiva. In: MÉSZÁROS, István. Para além do capital. São Paulo: Boitempo, 2011. p. 267-309

NEPOMUCENO, Bebel. Mulheres negras: Protagonismo ignorado. In: PINSKY, Carla Bassanezy; PEDRO, Joana Maria (orgs). Nova história das mulheres no Brasil. São Paulo: Contexto, 2013, p. 382-409.

OLIVEIRA, Leidiane Souza de. Feminismo e Luta de classes: emancipação das mulheres na perspectiva da totalidade. In: Encontro de Grupo de Estudos e Pesquisas Marxistas, VII, 2015, Campina Grande. Anais do VII Encontro de Grupo de Estudos e Pesquisas Marxistas. Campina Grande: UFCG 2015.

SAFIOTTI, Heleieth Iara Bongiovani. Gênero, patriarcado, violência. São Paulo: Fundação Perseu Abramo, 2004.

SANTOS, Silvana Mara de Morais dos. O pensamento da esquerda e a política de identidade: as particularidades da luta pela liberdade de orientação sexual. Tese (Doutorado em Serviço Social) - Universidade Federal de Pernambuco, Recife, 2005.

SARTI, Cynthia A, Feminismo e contexto: lições do caso brasileiro. Cadernos Pagu, n.16, p.31-482001.

SCHILD, Verônica. Feminismo e neoliberalismo na América Latina. Revista Outubro, n. 26, jul. 2016. Disponível em: <http://outubrorevista.com.br/feminismo-e-neoliberalismo-na-america-latina/>. Acesso em 13 de agosto de 2016

SILVA, Carmen; CAMURÇA, Silvia. Feminismo e Movimentos de Mulheres. Recife: SOS Corpo, 2013.

TABET, Paola. Mãos, instrumentos, armas. In: FERREIRA, Verônica et al (orgs.). O Patriarcado desvendado: teorias de três feministas materialistas: Collete Guillaumin, Paola Tabet e Nicole Claude Mathieu. Recife: SOS Corpo, 2014. p. 101-174.

TENORIO, Emilly Marques. Entre a polícia e as políticas: análise crítico-feminista da Lei Maria da Penha e das medidas de proteção de urgência judiciais. Dissertação (Mestrado em Política Social) - Universidade Federal do Espírito Santo. Vitória, 2017.

TONET, Ivo. Cidadania ou liberdade. Perspectivas. São Paulo, n. 22, p. 85-94, 1999.

\section{NOTAS}

\footnotetext{
${ }^{1}$ Uma versão compactada desse artigo foi aprovada no I Seminário Internacional sobre Trabalho e Reprodução Social da Universidade Federal de Alagoas, realizado entre 19 a 21/10/16.

${ }^{2}$ Cf. Tenorio (2017)

${ }^{3}$ Alguns exemplos das reportagens veiculadas foram na Revista Época: "A Primavera das Mulheres: Uma nova geração de ativistas toma as ruas e as redes sociais - e cria o movimento político mais importante do Brasil na atualidade", de 07 de novembro de 2015, disponível em: http://epoca.globo.com/vida/noticia/2015/11/primaveradas-mulheres.html; Revista Carta Capital: "A primavera é das mulheres" de 11 de novembro de 2015, disponível em http://www.cartacapital.com.br/sociedade/a-primavera-e-das-mulheres-8802.html e Brasil de Fato: "2015: a primavera das mulheres que floresceu", de 30 de dezembro de 2015, disponível em: http://www.brasildefato.com.br/node/33815. Todas acessadas em 20 de março de 2016.

${ }^{4}$ As autoras que compreendem a sociedade na perspectiva da análise indissociável entre sexo, raça e classe irão trabalhar com as categorias consubstancialidade ou interseccionalidade. Nesse artigo, adotaremos a categoria consubstancialidade, mas reconhecendo o alinhamento político com as pesquisadoras que trabalham interseccionalidade na mesma confluência teórica, considerando essas mesmas três dimensões imbricadas e estruturantes.

${ }^{5} \mathrm{O}$ sexo aqui é trabalhado enquanto relações sociais estruturantes e não em uma perspectiva biologizante.
} 

6 "las jerarquias sexuales siempre están al servicio de um proyeto de dominácion que sólo puede sustentarse a sí mesmi
através de la division, constantemente renovada, de aquéllos a se quienes governar" (FEDERICI, 2015a, p. 12) 